\title{
RELATO DE CASO \\ ÚLCERA DE MARJOLIN EM FERIDA POR QUEIMADURA: UM RELATO DE CASO
}

\section{MARJOLIN'S ULCER IN BURN WOUND: A CASE REPORT}

Henrique Pfeiffer Caiafa ${ }^{1}$; Renner Kesley Silva Lima ${ }^{1}$; Gabriela de Azevedo Moreira ${ }^{1}$; Bárbara Salles Santos ${ }^{1}$; Evandro Leite Bitencourt ${ }^{2}$; Sílvio Alves da Silva ${ }^{3}$.

\section{RESUMO}

A Úlcera de Marjolin é um tipo de lesão cutânea maligna que se desenvolve em áreas com lesões prévias. Inicialmente relacionada apenas às cicatrizes por queimadura, admite-se hoje que muitas outras condições podem evoluir para a transformação maligna. Sua patogenia ainda é mal definida, pressupondo envolvimento multifatorial, como inflamação tecidual crônica e imunossupressão. O tratamento é fundamentalmente cirúrgico, com remoção da área acometida com amplas margens de segurança. Outros métodos terapêuticos, como radioterapia, podem ser empregados. $O$ presente trabalho descreve a recorrência desta patologia em um paciente jovem abordado cirurgicamente previamente, com necessidade de nova intervenção, sendo realizada excisão da lesão durante internação e alta hospitalar para seguimento ambulatorial. Ressalta-se, portanto, a raridade da doença, seu potencial metastático e a necessidade de diagnóstico precoce para o melhor prognóstico.

Citação: Caiafa HP, Lima RKS, Moreira GA, Santos BS, Bitencourt EL, Silva SA (2020) ÚLCERA DE MARJOLIN EM FERIDA POR QUEIMADURA: UM RELATO DE CASO

Revista de Patologia do Tocantins, 10(4):.

\section{Instituição:}

1 Acadêmico de Medicina, Universidade Federal do Tocantins, Palmas, Tocantins, Brasil.

2 Graduado em Química; Mestre em Química; Acadêmico Medicina, Universidade Federal do Tocantins, Palmas, Brasil; Pesquisador Instituto Médico Legal do Tocantins (IML/TO), Palmas, Brasil.

3 Graduado em Medicina pela Universidade Federal do Maranhão (UFMA). Médico Cirurgião Geral e Cirurgião Vascular pelo Hospital Jaraguá em São Paulo. Mestre em Ciências da Saúde pela UFT. Professor efetivo do Curso de Medicina da UFT

Autor correspondente: Henrique Pfeiffer Caiafa; hpcaiafa@gmail.com

Editor: Carvalho A. A. B. Medicina, Universidade Federal do Tocantins, Brasil.

Publicado: 18 de outubro de 2020.

Direitos Autorais: (C) 2020 Caiafa et al. Este é um artigo de acesso aberto que permite o uso, a distribuição e a reprodução sem restrições em qualquer meio, desde que o autor original e a fonte sejam creditados.

Conflito de interesses: os autores declararam que não existem conflitos de interesses.

\begin{abstract}
Marjolin's Ulcer is a type of malignant skin lesion that develops in areas with previous lesions. Initially related only to scars from burns but, currently it is admitted that many other conditions can evolve to the malignant form. The pathogenesis is still poorly defined, and presupposes multifactorial causes, such as chronic tissue inflammation and immunosuppression. The treatment is fundamentally surgical, with removal of the affected area with wide safety margins. Other therapeutic methods, such radiotherapy, can be used. The present study describes the recurrence of this pathology in a young patient who had been surgically treated previously, in need of new intervention, with excision of the lesion during hospitalization and discharge for outpatient follow-up. Therefore, the rarity of the disease, the metastatic potential and the need for early diagnosis for the best prognosis are highlighted

Keywords: Skin Ulcer; Burns; Squamous Cell Carcinoma.
\end{abstract}


Jean-Nicholas Marjolin descreveu, em 1828, modificações de cicatrizes causadas por queimaduras em lesões ulceradas ${ }^{1}$. A transformação de uma cicatriz ou úlcera crônica em uma neoplasia, portanto, passou a ser definida como Úlcera de Marjolin (UM). Historicamente, esse termo referia-se apenas aos casos em que a lesão inicial era uma cicatriz de queimadura. Atualmente, porém, reconhece-se que diversas condições que causem úlceras crônicas podem levar ao aparecimento da UM, tais como úlceras de pressão, úlceras diabéticas, osteomielite, entre outras ${ }^{2,3}$.

Ainda não bem esclarecida, pressupõe-se que a patogenia envolve múltiplos fatores, entre os quais: inflamação crônica, com liberação de citocinas e fatores de crescimento que induzem proliferação celular descontrolada, imunossupressão, alterações histológicas na vascularização e drenagem venosa e linfática deficientes, levando à menor exposição das áreas lesadas à vigilância do sistema imune ${ }^{3,}$ ${ }^{4}$.Tais condições facilitariam a iniciação e a promoção da carcinogênese ${ }^{5}$.

Quando comparadas aos carcinomas espinocelulares originados em áreas teciduais previamente sadias, as lesões da UM apresentam maior agressividade. O tempo necessário para a transformação maligna é, na maioria dos casos, prolongado, com uma média de cerca de 30 anos, sendo que períodos tão longos quando 75 anos ou tão curtos quanto poucas semanas já foram relatados ${ }^{5,6,7}$. Existem controvérsias sobre o seu potencial metastático. Alguns estudos consideram a UM com alto potencial, podendo chegar a cerca de $30 \%$ dos casos diagnosticados; outros, entretanto, trazem porcentagens tão baixas quanto $3,6 \%^{3,8}$.

O diagnóstico se dá pelo estudo histopatológico e na maioria das vezes ocorre tardiamente, quando a doença se apresenta de forma avançada, já com alterações consideráveis. Devido a esse fato, o prognóstico dos pacientes com UM costuma ser reservado ${ }^{3}$.

É consenso na literatura que o tratamento para a UM, na pluralidade dos casos, é cirúrgico. Indica-se a excisão de todo o tecido acometido com margens de, no mínimo, $2 \mathrm{~cm}$ (incluindo pele, músculos e fáscia). Idealmente, realiza-se a biópsia por congelação para se certificar que as margens estão livres. A remoção linfonodal profilática permanece controversa ${ }^{8}$. Entretanto, quando há linfonodos palpáveis, é mandatória a remoção cirúrgica ${ }^{4,6}$. A radioterapia pode ser considerada como método adjuvante após a ressecção cirúrgica da lesão ou como terapia primária, nos casos de irressecabilidade tumoral ${ }^{4,8}$. Porém, deve-se ressaltar que a UM apresenta uma pobre resposta à radioterapia 9 .

Após o tratamento cirúrgico as chances de existir um tumor residual podem chegar a $58 \%$ e de recidiva a $33 \%$. A sobrevida gira em média entre $52 \%, 34 \%$ e $23 \%$ em 5 , 10 e 20 anos respectivamente ${ }^{3}$.

Considerando o caráter agressivo da UM e o maior potencial metastático quando comparado a um CEC sem lesão prévia, este relato tem como objetivo ressaltar a importância do diagnóstico precoce para melhor prognóstico do paciente, tendo em vista os diagnósticos diferenciais que por vezes postergam o tratamento adequado
Paciente O. V. S., 24 anos, solteiro, masculino, pardo, desempregado, natural de Confresa - MT, residente e procedente de Palmas - TO, admitido no serviço de Cirurgia Oncológica do Hospital Geral Público de Palmas (HGPP) em janeiro de 2020, local no qual já fazia acompanhamento com a especialidade supracitada devido a um CEC diagnosticado em 2018, localizado em região plantar direita. À exceção do histórico neoplásico, nega patologias prévias ou uso contínuo de medicamentos.

Procedeu-se à internação pela necessidade de tratamento cirúrgico com coleta de material para anatomopatológico de uma lesão ulcerada em região plantar do pé direito, de aproximadamente $4,0 \mathrm{~cm}$ em seu maior diâmetro, com bordas precisas, elevadas e irregulares, iniciada em outubro de 2019, com presença de área de necrose (Figura 1). A lesão estava associada a dor de moderada intensidade (quantificada como 6 na escala analógica da dor), prurido perilesional e dificuldade de deambulação. Negou febre, parestesia e edema. O resultado do anatomopatológico de produto de biópsia da referida lesão mostrou diagnóstico de carcinoma epidermoide invasor bem diferenciado grau I de Broders, com invasão perineural.

Durante investigação de histórico patológico pregresso, relatou, aos dois anos de idade, acidente doméstico com consequente queimadura térmica em ambas as regiões plantares, com permanência de deformidades, extensa cicatriz fibrosa e incapacidade de mobilização de artelhos. No ano de 2018, foi diagnosticado com carcinoma epidermoide invasor em região plantar direita, grau I de Broders, com comprometimento neural. Recebeu tratamento cirúrgico no mesmo ano, com anatomopatológico evidenciando margens cirúrgicas livres.

Figura 1: Foto da lesão em planta de pé direito no dia do procedimento cirúrgico. A: pé inteiro; B: evidenciando a lesão.

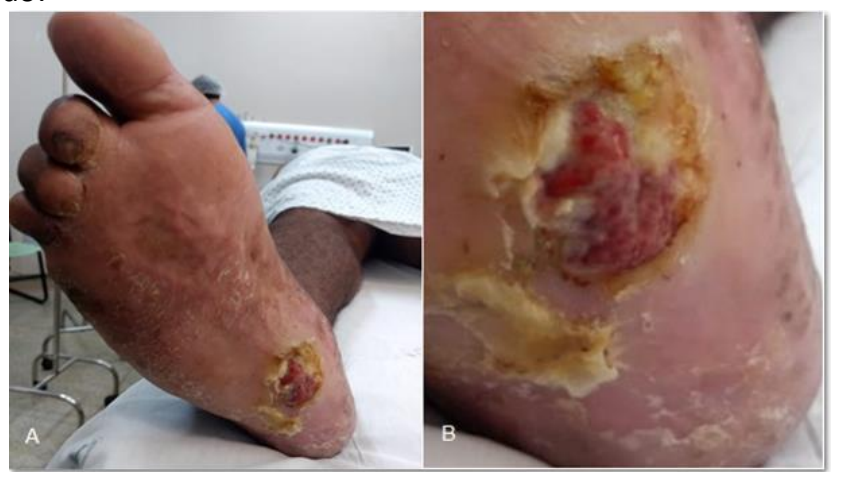

Fonte: Próprio Autor, 2020.

A internação hospitalar foi realizada em caráter eletivo, com o objetivo de exérese da lesão. O tratamento cirúrgico foi realizado sob raquianestesia e consistiu em incisão circular ao redor da lesão, dissecção de planos até a fáscia plantar do pé direito, sem intercorrências, com remoção macroscópica da área acometida (Figura 2) e envio da peça para estudo anatomopatológico. Recebeu alta hospitalar dois dias após a realização do procedimento cirúrgico com orientações para seguimento ambulatorial com a equipe de Cirurgia Oncológica do HGPP. 
Figura 2: Foto da lesão em planta de pé direito após o procedimento cirúrgico.

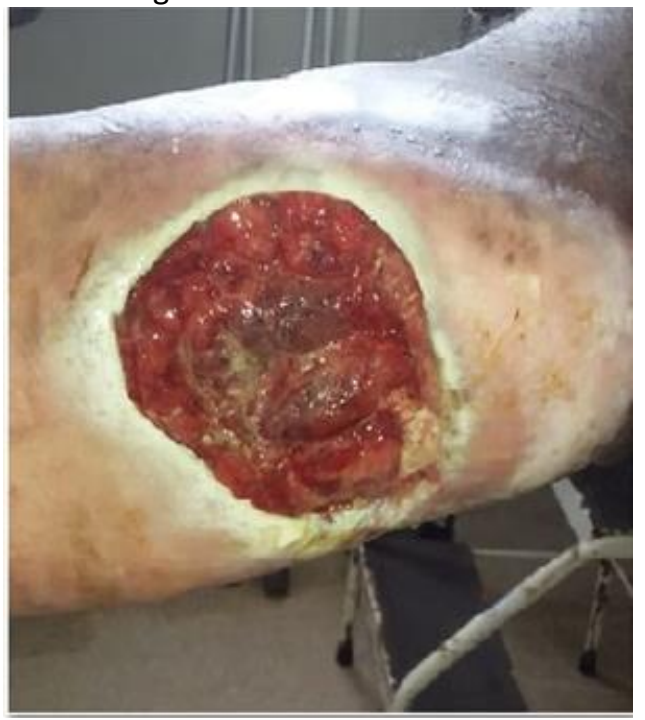

Fonte: Próprio autor, 2020.

No presente caso, percebe-se grande concordância em relação aos relatos da literatura. Epidemiologicamente, tem-se um paciente do sexo masculino, vítima de queimadura, com surgimento da neoplasia em membro inferior. Tal perfil é o mais comumente relatado.

É importante ressaltar a importância de tratamento adequado das lesões, para que haja menor chance de sua evolução para uma neoplasia. Em queimaduras, por exemplo, pode-se optar por tratamento com enxerto, assim evitando a cronificação do processo inflamatório cicatricial ${ }^{10}$. É de extrema importância a vigilância para evitar a formação de lesões precursoras, e quando já formadas conduzir de modo adequado para prevenir a formação de $\mathrm{UM}^{3}$.

\section{CONCLUSÃO}

Embora considerada uma entidade rara, cuja taxa de incidência amplamente aceita na literatura seja de $2 \%$ após queimaduras, especialmente nas queimaduras de 20 e 3 은 graus, atenção redobrada deve ser dada aos pacientes com histórico de lesões crônicas, pois a UM comporta-se como neoplasia agressiva, especialmente quando há acometimento linfonodal, e com potencial mutilante, visto que o tratamento de escolha é a remoção cirúrgica com amplas margens. No referido caso clínico, realizou-se a abordagem cirúrgica para posterior acompanhamento ambulatorial conforme resultado da análise anatomopatológica. A suspeita clínica em casos de pacientes com histórico de queimaduras e úlceras crônicas deve ser precoce para se obter melhor prognóstico. acometidas por condições como úlceras de pressão, úlceras angiodérmicas, fístulas crônicas, lúpus eritematoso discóide, entre outras ${ }^{2,4}$.

Doenças como a leishmaniose tegumentar americana (LTA), paracoccidioidomicose cutânea, cromomicose, e tuberculose cutânea são consideradas os principais diagnósticos diferenciais da UM, e a utilização de antimicrobianos em geral acarreta no atraso do diagnóstico correto $^{3}$. Em uma região endêmica para LTA, como é o local de origem deste relato, é esperado que seja feita investigação para tal infecção, como ocorreu com o paciente no ano de 2018.

De acordo com o tempo de evolução, a UM pode ser classificada como aguda, quando seu surgimento ocorre em até 1 ano após a injúria tecidual inicial, e crônica, quando seu aparecimento se dá após 1 ano da injúria inicial, sendo esta última a manifestação mais comum ${ }^{3,6} .0$ período de latência entre a injúria tecidual inicial e a manifestação da UM observado no caso exposto aproxima-se ao período frequentemente relatado na literatura, sendo ultrapassadas duas décadas entre os eventos.

Dentre os tipos histológicos da UM, o Carcinoma Espinocelular (CEC) é a forma de apresentação mais comum, correspondendo a mais de $70 \%$ dos casos. O Carcinoma Basocelular ( $\mathrm{CBC}$ ) aparece em segundo lugar na ordem de frequência, sendo responsável por até $10 \%$ das manifestações. Melanomas e Sarcomas já foram relatados, porém são considerados casos mais raros ${ }^{3}$. O CEC geralmente é mais encontrado nas extremidades, principalmente nas inferiores (40\%) seguido pela calota craniana (30\%), membros superiores $(20 \%)$ e tronco $(10 \%)^{1}$.

\section{REFERÊNCIAS}

1 - PEREIRA, S. P. Úlcera de Marjolin: Revisão Integrativa. 2019. 28 f. Monografia (Especialização em Enfermagem em Estomaterapia) - Universidade Federal de Minas Gerais, Belo Horizonte, 2019.

2 - AZULAY, R. D.; AZULAY, D. R. Dermatologia. 7. ed. Rio de Janeiro: Guanabara Koogan, 2017.

3 - LEONARDI, D. F.; OLIVEIRA, D. S.; FRANZOI M. A. Úlcera de Marjolin em cicatriz de queimadura: revisão de literatura. Rev Bras Queimaduras 2013;12(1):49-52. Disponível em: <http://rbqueimaduras.org.br/details/144/ptBR/ulcera-de-marjolin-em-cicatriz-de-queimadura--revisao-deliteratura>. Acesso em: 28/01/2020.

4 - LI, D. et al. Clinical features and expression patterns for burn patients developed marjolin ulcer. Journal of Burn Care \& Research, 2019.

5 - BAZALIŃSKI, D.; PRZYBEK-MITA, J.; BARAŃSKA, B.; WIĘCH, P. Marjolin's ulcer in chronic wounds - review of available literature. Contemp Oncol (Pozn) 21 (3): 197-202. 2017.

6 - CHATURVEDI, G. et al. Marjolin Ulcer: An Observational Epidemiological Study From a Tertiary Care Centre in India. Annals of Plastic Surgery, v. 83, n. 5, p. 518522, 2019.

7 - SIMÃO, T. S.; ALMEIDA, P. C. C.; FAIWICHOW, L. Úlcera de Marjolin: visão atualizada. Rev Bras Queimaduras 2012;11(4):251-253. Disponível em: 
BR/ulcera-de-marjolin--visao-atualizada>. Acesso em: 27/01/2020.

8 - XIANG, F; SONG, H. P.; HUANG, Y. S. Clinical features and treatment of 140 cases of Marjolin's ulcer at a major burn center in southwest China. Experimental and therapeutic medicine, v. 17, n. 5,p . 3403-3410, 2019.

9 - XIAO, H. et al. A review of 31 cases of Marjolin's ulcer on scalp: Is it necessary to preventively remove the scar? International Wound Journal, v. 16, n. 2, p. 479-485, 2019.

10 - DAS, K.K. et al. Incidences of malignancy in chronic burn scar ulcers: experience from Bangladesh. Burns. v. 41, n. 6, p. 1315-1321, 2015. 